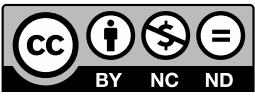

Estudos Teológicos foi licenciado com uma Licença Creative Commons Atribuição - NãoComercial - SemDerivados 3.0 Não Adaptada

http://dx.doi.org/10.22351/etv59i2.3779

\title{
OS MÉTODOS HISTÓRICO-CRÍTICOS: PRESSUPOSTOS E PAUTAS PARA RENOVAÇão ${ }^{1}$
}

\author{
The historical-critical methods: \\ presuppositions and agenda for renew
}

Paulo Nogueira ${ }^{2}$

\begin{abstract}
A verdade não veio nua ao mundo, mas em símbolos e imagens. De outra forma, não se poderia compreendê-la. Há um renascer, e uma imagem do renascer. Na verdade, é necessário renascer pela imagem [...] (Evangelho de Felipe, 67).
\end{abstract}

Resumo: Os métodos histórico-críticos (MHC) de exegese bíblica tiveram um papel fundamental na formação de intérpretes na América Latina, a despeito de outras abordagens concorrentes ou complementares. Partindo do pressuposto da validade e importância dessa abordagem para os estudos bíblicos contemporâneos, este artigo se propõe a revisitar criticamente três dos seus procedimentos básicos, a saber: a ênfase na história factual, leitura demitizadora e uso indiscriminado do conceito de "comunidade". Propomos uma discussão rumo à atualização dessa abordagem a partir de conceitos da história cultural, de estudos de linguagem mítica e metafórica e de cultura popular no mundo antigo.

Palavras-chave: Métodos histórico-críticos. História cultural. Mito. Simbolismo. Interpretação do Novo Testamento.

Abstract: The historic-critical methods (MHC) of Biblical exegesis had a key role in the formation of Biblical interpreters in Latin-America, besides other concurrent or optional approaches. Recognizing the validity of the MHC for the Biblical studies today, this article intends to critically analyze three of its basic procedures: the emphasis on the factual history, the demythologizing reading and the indiscriminate employment of the concept "community". We propose then a discussion towards a renewal of this approach considering the cultural history, the studies on mythic and metaphorical language and of popular culture in the Ancient World.

Keywords: Historic-critical methods. Cultural history. Myth, Symbolism. New Testament interpretation.

1 O artigo foi recebido em 20 de agosto de 2019 e aprovado em 18 de novembro de 2019 com base nas avaliações dos pareceristas ad hoc.

2 Doutor, bolsista produtividade CNPq, nível 2. Universidade Metodista de São Paulo, São Bernardo do Campo, SP. E-mail: pasn777@outlook.com 


\section{Introdução}

Minha geração aprendeu exegese bíblica nos anos 1980 por meio dos métodos histórico-críticos (MHC). Muitos de nós provínhamos de ambientes evangélicos conservadores, de seminários teológicos nos quais interpretar corretamente a Bíblia significava traduzir os textos do hebraico e do grego e harmonizar o que se lia com os pressupostos teológicos do grupo. O texto, revelação inspirada, era uma grandeza que "dizia por si só", ainda que de fato houvesse muitas mediações em jogo. Diante desse modelo de interpretação monótono e pouco instigante, o aprendizado dos métodos histórico-críticos (MHC) era uma necessidade premente. O texto bíblico se apresentava nesse procedimento exegético tradicional como uma grandeza estática, a-histórica, sem vida. O ápice desse modelo exegético se daria em outros espaços de reflexão teológica, principalmente no trabalho do teólogo sistemático, que transformava esse texto inerte em proposições sobre Deus, a salvação, a igreja etc. O valor do texto estaria em outro lugar que não na construção de modelos de mundo em suas imagens e metáforas, nem no ritmo de suas narrativas. $\mathrm{O}$ texto teria valor apesar desses elementos, como portador de verdades eternas e imutáveis.

O encontro com os MHC nos transportou para outro universo de interpretação. O texto ganhava história pela primeira vez. Seja na história de sua preservação em antigos, divergentes e incompletos manuscritos, seja no levantamento das fontes dentro de um texto, das vozes sociais e religiosas que ainda ecoavam dentro dele. Era renovador também poder estudar o contexto dos textos, evocados pela expressão algo mistificada, porém simples em seu idioma de origem, o Sitz im Leben (ou: "lugar na vida"). O texto antes entendido como revelação divina era agora estudado na relação com os impérios do mundo antigo, como expressão de grupos sociais, entendido dentro do contexto de embates de tendências teológicas rivais. Isso tornou para mim, e para muitos de minha geração, a exegese bíblica a rainha das ciências teológicas, o seu coração.

Por ter estudado no ISEDET, em Buenos Aires, meu primeiro manual de MHC foi o consagrado livro de Heinrich Zimmermann, Neutestamentliche Methodenlehre. Darstellung der historisch-kritischen Methode, de 1967, que então líamos em tradução espanhola. ${ }^{3}$ A obra de Zimmermann era austera, didática no limite, e apresentava os MHC em seus quatro eixos fundamentais: a) a crítica textual, b) a crítica literária, c) a história das formas, e d) a crítica da redação. Essa composição, hoje clássica, e usada em cursos de exegese pelo mundo afora, só era possível nos anos de 1960, quando recém se incorporava a crítica da redação aos MHC. Criada por Hans Conzelman ${ }^{4}$ e Willi Marxsen ${ }^{5}$, entre outros, nos anos 1950, a crítica da redação havia sido concebida como reação à fragmentação do texto bíblico da história das formas. Com esse quarteto era possível analisar o texto bíblico cientificamente, em sua historicida-

3 ZIMMERMANN, Heinrich. Los métodos histórico-críticos en el Nuevo Testamento. Madrid: Biblioteca de Autores Cristianos, 1969.

4 CONZELMAN, Hans. Die Mitte der Zeit. Studien zur Theologie des Lukas. Tübingen: Mohr, 1954.

5 MARXSEN, Willi. Der Evangelist Markus. Studien zur Redaktiongeschichte des Evangeliums. Göttingen: Vandenhoeck und Ruprecht, 1959. 
de, desde a fixação do texto mais antigo, eventualmente a reconstrução do original, suas fontes, sua circulação na oralidade e a sua redação final, na qual a teologia de um escrito se fazia mais evidente.

Não tardaram a aparecer desafios aos MHC, principalmente originados em ambiente francófono, que ofereciam como alternativa a análise estrutural, tal como promovida, por exemplo, pela equipe Cahiers Evangile, a cargo de Etienne Charpentier ${ }^{6}$. Eram os anos 1970 e os métodos estruturalistas ainda estavam em alta nas ciências humanas. Com o objetivo de estudar as estruturas discursivas no plano da imanência, a abordagem semiótica escolhida foi a da Greimas, com suas fórmulas, equações, quadrados lógicos e terminologia ultraespecializada, que aspirava a uma aura de cientificidade. Não que os MHC também não aspirassem a cientificidade e não tivessem seu jargão técnico; no entanto, creio que a escolha pela semiótica estrutural de Greimas ao invés do modelo de R. Barthes, por exemplo, foi um dos fatores decisivos para seu fracasso. De qualquer forma, estabeleceu-se na América Latina nos anos 1980 um vívido debate entre exegetas histórico-críticos e os estruturalistas, com vitória clara dos primeiros, afinal, no auge da Teologia da Libertação, havia um apreço pelas abordagens historiográficas de corte marxista, nas quais o estudo das determinantes econômicas e políticas dos textos religiosos era fundamental. ${ }^{7}$

Os MHC, no entanto, apesar de terem se tornado quase que canônicos nos currículos de faculdades de teologia acadêmicas, tiveram que reagir, a partir dos anos 1980 , a questionamentos que lhe foram impostos pelas abordagens linguísticas e discursivas. Em resposta a essa necessidade de renovação surgiram obras que buscaram renovar os MHC e atualizá-los em relação a procedimentos de análise linguística do final do século XX. Podemos citar dois autores que procederam, cada qual à sua maneira, a essa atualização. Wilhelm Egger publicou em 1987 sua Methodenlehre zum Neuen Testament, com o chamativo subtítulo: Einführung in Linguistische und historisch-kritische Methoden ${ }^{8}$. Egger tinha como objetivo atualizar os já envelhecidos MHC com procedimentos sincrônicos, como a análise linguístico-sintática, semântica e pragmática. Alguns anos antes, Klaus Berger publicou sua Exegese des Neuen Testaments $^{9}$, que, ainda que parecesse mais um manual com os passos tradicionais dos MHC, buscou intensamente dialogar com conceitos da teoria literária e da linguística, oferecendo novas perguntas aos textos, a partir de procedimentos inovadores. Também não podemos deixar de mencionar a importância para a renovação dos MHC que teve, a partir do final dos anos 1970 e com intensidade nos anos 1980, a chamada sociologia do Novo Testamento. Uma das obras pioneiras nesse movimento foi a Soziologie der Jesusbewegung. Ein Beitrag zur Entstehungsgeschichte des Urchristen-

\footnotetext{
CHARPENTIER, Etienne. Iniciación en el análisis estructural. Estella: Verbo Divino, 1978.

7 Na contramão da preferência latino-americana pelos métodos histórico-críticos, podemos citar a obra de ZABATIERO, Júlio. Manual de Exegese. São Paulo: Hagnos, 2007; que oferece uma metodologia exegética que assume abordagem e terminologia greimasianas.

8 EGGER, Wilhelm. Metodologia do Novo Testamento: Introdução aos métodos linguísticos e históricocríticos. 2. ed. São Paulo: Loyola, 2005.

9 BERGER, Klaus. Exegese des Neuen Testaments. Heidelberg: UTB Quelle \& Meyer, 1984.
} 
tums $^{10}$, de Gerd Theissen. Na sociologia do Novo Testamento, elementos do contexto econômico, social e político, que eram tratados de forma incipiente no conceito tradicional de Sitz im Leben, passaram a ser analisados de forma mais técnica por meio de instrumentais das ciências sociais.

Os MHC estão longe de estarem em desuso na pesquisa bíblica internacional e latino-americana. Basta mencionar o sucesso do mais completo manual brasileiro sobre o tema, o Exegese do Novo Testamento - Manual de metodologia, de Uwe Wegner ${ }^{11}$, publicado pela primeira vez em 1998, que se encontra já na $8^{\mathrm{a}}$ edição. Ainda que esse manual seja do final do século XX, ele mantém em sua essência um posicionamento metodológico clássico, consolidado pelos $\mathrm{MHC}$.

Apesar do sucesso dos MHC na América Latina, entendemos, no entanto, que ainda é necessário um debate de caráter teórico e metodológico no qual se pergunte pela sua pertinência e atualidade. Os MHC, a despeito de certa aura de cientificidade objetiva, têm pressupostos que determinam seu olhar para o texto, o que permite que certas perguntas sejam feitas. A linguística, as semióticas discursivas, as novas historiografias e os estudos culturais e de gênero, entre outras abordagens, seguem lançando questões sobre nosso conceito exegético de texto, de história, de leitura, de sujeito, derivado do labor histórico-crítico, tributário de concepções teóricas do final do século XIX e do começo do século XX.

Nosso objetivo neste artigo é, além de reconhecer a importância que os MHC tiveram e ainda têm na formação de exegetas latino-americanos, propor um conjunto de questões para sua renovação e para a superação de certos pressupostos, que a nosso ver não atendem as perspectivas contemporâneas sensíveis às dinâmicas culturais. Devido ao espaço que nos é disponível em um artigo científico, pretendemos oferecer um conjunto articulado de pautas para discussão e renovação dos $M H C$ que merecem desenvolvimento posterior. Para evidenciar sua relevância, elas devem ser apresentadas em conjunto, pois fazem parte de uma mesma compreensão de texto e de história. Nossa discussão e exemplos se limitam aos MHC na exegese do Novo Testamento.

\section{Pressupostos dos métodos histórico-críticos e possíveis alternativas}

\section{Do factual ao cultural: o abandono de uma obsessão moderna}

A exegese histórico-crítica é uma herdeira legítima do iluminismo e da modernidade em seus pressupostos científicos e visão de mundo. A exegese desenvolveu-se nas faculdades de teologia evangélicas alemãs nos séculos XVIII e XIX, no contexto da teologia liberal, como um corretivo da visão ingênua dos consumidores finais do texto bíblico, os adeptos religiosos, e como oposição ao dogmatismo teológico eclesiástico. Ao dogma, a exegese promovida pelo liberalismo teológico buscava contra-

\footnotetext{
10 THEISSEN, Gerd. Soziologie der Jesusbewegung. Ein Beitrag zur Entstehungsgeschichte des Urchristentums. München: Chr. Kaiser Verlag, 1977.

11 WEGNER, Uwe. Exegese do Novo Testamento: manual de metodologia. São Leopoldo: EST; Sinodal, 1998.
} 
por um saber científico embasado em análise filológica e histórica das fontes, com a aplicação de critérios científicos. Nesse esforço intelectual surgiu a crítica bíblica. Os relatos do Antigo e do Novo Testamentos passaram a ser avaliados no confronto com fontes históricas e com dados arqueológicos. Isso proporcionou um novo paradigma no estudo da religião no mundo antigo. $\mathrm{Na}$ interpretação do Novo Testamento, um dos tópicos que ganhou notoriedade e se tornou um espaço de experimentações foi a pesquisa do Jesus histórico, da qual trataremos em seguida. Ao se proceder a uma investigação histórica e científica do texto bíblico, logo se constatou certa inadequação do mesmo com a histórica factual. Imprecisões, discrepâncias, informações anacrônicas, relatos fantásticos saltaram aos olhos quando comparados com a austeridade do factual. A historiografia científica só pode dar conta do que pode ser explicado por meio de causas verificáveis e repetíveis. Essa tensão entre o elemento fantasioso do texto bíblico e a busca rigorosa do factual por parte da exegese acadêmica criou uma esquizofrenia de fundo na hermenêutica bíblica na modernidade.

A historiografia do século XX, em especial a chamada Nova História, e mais especificamente a chamada história cultural, desafiou esse paradigma da historiografia moderna e sua obsessão pelo factual. Na verdade, já no século XIX havia historiadores, como Gustav Droysen e Theodor Mommsen, que insistiam que a ciência histórica deveria levar em consideração os processos interpretativos na pesquisa historiográfica. ${ }^{12}$ Mas é sobretudo na historiografia francesa, a partir dos anos 1970, que se desenvolvem, ou se redescobrem, novas práticas historiográficas. $\mathrm{O}$ foco na história cultural não é colocado na reconstrução de fatos e na atenção exclusiva ao âmbito político e econômico. A história cultural, que em muitos aspectos se sobrepõe à história das mentalidades, está interessada nas estruturas de percepção e de classificação da experiência e nas práticas de memória de uma sociedade. Ela é uma historiografia que tem preocupação "com o simbólico e com suas interpretações"13. Enquanto na historiografia tradicional são analisados prioritariamente os fatos, em especial políticos, econômicos e militares, na história cultural as próprias categorias e as práticas com que as pessoas comuns organizam seu cotidiano e sua vida social merecem atenção, enquanto são organizadas em um sistema semiótico. ${ }^{14}$

Um caso extremo de positivismo historiográfico nos MHC pode ser encontrado na pesquisa do Jesus histórico. Essa pesquisa promovida em ambiente acadêmico no hemisfério Norte tem por foco uma reconstrução plausível da história de Jesus de Nazaré a partir de critérios explícitos, como antiguidade e multiplicidade das fontes, enquadramento de plausibilidade dos fatos na história e cultura do judaísmo e do mundo mediterrâneo de seu contexto. Cria-se assim uma cisão entre as primeiras de-

${ }^{12}$ Cf. SCHRÖTER, Jens. Neutestamentliche Wissenschaft jenseits des Historismus. Neuere Entwicklungen in der Geschichtstheorie und ihre Bedeutung für die Exegese urchristlicher Schriften. Theologische Literaturzeitung, Set. 2003, p. 855-866, e ZIMMERMANN, Ruben. Geschichtstheorien und Neues Testament. Gedächtnis, Diskurs, Kultur und Narration in der historiographischen Diskussion. Early Christianity, 2, p. 417-444, 2011.

13 BURKE, Peter. O que é história cultural? Rio de Janeiro: Jorge Zahar, 2005. p. 10.

${ }^{14}$ GUREVICH, A. J. Categories of Medieval Culture. London: Routledge \& Kegan Paul, 1985. p.13ss. 
voções ao Cristo (as chamadas "cristologias"), que seriam relatos posteriores sobre o significado de Jesus para as comunidades cristãs, e os fatos históricos constitutivos da vida de Jesus de Nazaré. O curioso nesse procedimento é que o que se define como fato histórico, como fato atribuível à vida de Jesus de Nazaré, é na verdade fruto de práticas modernas. No famoso Jesus Seminar os procedimentos são bem definidos: acadêmicos de universidades de prestígio do Atlântico Norte, boa parte deles religiosos ou clérigos, na maioria homens, de classe média alta, definem por meio de votação democrática, a partir de critérios definidos por todos, se um dito ou relato pode ser atribuído ao Jesus histórico. É como se a vida e atuação de um profeta, milagreiro e visionário do mundo antigo, das margens do Império Romano, pudessem ser definidas por esses critérios. Nenhuma surpresa, incoerência, êxtase ou improvisação frente a oposições e obstáculos imprevistos ou necessários poderia ter sido parte dessa história. O mais grave é que o impacto que Jesus de Nazaré teria causado entre seus seguidores não pudesse ser parte dessa história, tornando-se um empecilho à sua reconstrução. Não é à toa que uma das reconstruções do Jesus histórico do final de século, a de John Dominic Crossan, chega a um resultado pouco empolgante, de que Jesus era um mago que desafiava o poder religioso do Templo, que pregava a chegada do Reino aos pobres e promovia comensalidade aberta. Esse Jesus só pode corresponder aos limites do quadro histórico e metodológico de sua reconstrução. Os MHC fornecem o pano de fundo intelectual e histórico dessa reconstrução. A busca pelo Jesus histórico, com suas peculiaridades, teria sido impossível sem eles.

O predomínio do factual, no entanto, extrapola o âmbito da pesquisa do Jesus histórico, passando a determinar a leitura de textos ainda mais marcados pela imaginação religiosa, como o Apocalipse de João. O Apocalipse é estudado pelos MHC a partir do que se convencionou chamar zeitgeschichtliche Auslegung, que traduzimos por "interpretação histórica contextual", ou seja, cada visão ou parte de visão do Apocalipse deveria corresponder a um evento ou a uma instituição de sua sociedade. O caráter predominante dos fatos sobre a composição imagética da visão determina a interpretação em direção ao que importa: a história factual e suas determinantes, como os fatores econômicos, políticos e militares. Um exemplo desse tipo de interpretação podemos encontrar na forma como os comentaristas analisam o terceiro selo, no qual é visto um cavaleiro que cavalga um cavalo negro com uma balança na mão. Uma voz no meio dos seres viventes diz: "Um quilo de trigo por um denário e três quilos de cevada por um denário. Não prejudiques o azeite e o vinho" $(6,6)$. Nos comentários, essa passagem é relacionada com o edito do imperador Domiciano do ano 92, segundo o qual ele teria proibido novas vinhas de serem plantadas na Itália, além de ordenar que metade das vinhas nas províncias fosse destruída. Esse edito gerou revolta na Ásia Menor, onde estavam as cidades em que viviam os leitores do Apocalipse. Ou seja, a visão do terceiro cavaleiro é relacionada a um evento histórico concreto e só assim pode fazer sentido. ${ }^{15} \mathrm{O}$

\footnotetext{
${ }^{15}$ Mais sobre essa interpretação e suas variantes em comentários como, por exemplo, o de MÜLLER, U. B. Die Offenbarung des Johannes. Gütersloh: Gütersloher Verlagshaus Gerd Mohn, 1984. p.168-169. (ÖTK).
} 
conjunto das visões narradas, nas quais demônios militares que promovem subjugação, guerra, fome e morte violenta, apresentados em conjunto como o início da abertura dos selos escatológicos, deve ser subjugado à facticidade histórica e corresponder a eventos concretos. Abaixo observaremos que não se trata apenas do primado dos fatos sobre as categorias da imaginação religiosa, mas também de imposição de uma agenda das elites sobre a dos grupos subalternos de uma sociedade.

Na pesquisa bíblica contemporânea, inclusive na Alemanha, berço dos métodos histórico-críticos, há vozes que apontam para a necessidade de uma renovação da perspectiva historiográfica dos MHC. Destaco entre eles um artigo seminal de Ruben Zimmermann, intitulado Geschichtstheorien und Neues Testament. Gedächtnis, Diskurs, Kultur und Narration (Teorias de história e o Novo Testamento. Memória, discurso, cultura e narrativa), que propõe uma pauta de renovação historiográfica nos MHC no desejo de superação da busca exclusiva e prioritária pelo factual. Ele propõe substituir esse conceito de história factual por outras abordagens mais apropriadas ao texto e à imaginação religiosa como memória e narrativa. $\mathrm{O}$ autor questiona, portanto, o modelo estabelecido dos MHC ao propor a substituição da busca por fatos na origem do cristianismo pelo estudo de memórias culturais, o que, em sua opinião, representaria uma mudança de paradigma na pesquisa, em especial na investigação sobre Jesus de Nazaré. ${ }^{16}$ As informações sobre Jesus não seriam acessíveis ao exegeta - ao exegeta como historiador - sem a mediação das memórias, e dos gêneros literários narrativos que as organizaram e lhes deram forma. Na verdade, alinhado com historiadores que enfatizam o trabalho historiográfico como trabalho narrativo e literário, de construção de estruturas narrativas ficcionais como a historiografia, na linha de Hayden White, entre outros, Zimmermann insiste numa narratividade radical das testemunhas mais antigas do Novo Testamento. Ele chega a afirmar que "não existe facticidade pura" ${ }^{17}$, ou seja, a ordem dos acontecimentos já se dá na mediação narrativa do texto. A experiência de eventos e de fatos se organiza por meio de estruturas narrativas. Nesse sentido, a história de Jesus está em contínuo processo de interpretação, desde a interpretação que ele dava a si mesmo até a interpretação de outros em seu contexto mais próximo. A suposta realidade histórica só é possível dentro de sistemas de coordenadas da linguagem.

O conceito de história da história cultural e dos estudos culturais deveria impactar na exegese bíblica e nos permitir relativizar, quando não abandonar, a busca por bructa facta, ou ipsissima verba Jesu, que, em minha opinião, é um fetiche da modernidade, somado a um desejo protestante de obter acesso não mediado às origens. Sem os processos narrativos ficcionais inerentes na autoconsciência dos sujeitos, e nos processos mais primários de narração dos eventos experimentados na cultura, com suas categorias específicas, não é possível qualquer concepção de realidade. ${ }^{18}$

16 ZIMMERMANN, 2011, p. 420.

${ }_{17}$ ZIMMERMANN, 2011, p. 433.

${ }^{18}$ Ver a respeito da categoria narrativa e cognitiva de ficcionalidade e seu papel no estudo da religião em NOGUEIRA, Paulo A. S. Religião e ficcionalidade: modos de as linguagens religiosas versarem sobre o 
Revisão do conceito de mito: de problema hermenêutico a motor simbólico do Novo Testamento

O foco da exegese histórico-crítica nos fatos históricos, compreendidos como fatos positivos, submetidos à interpretação (ou a leituras teológicas) apenas num segundo momento, está diretamente relacionado a outro aspecto do pano de fundo moderno dessa epistemologia. Trata-se do problema de como lidar com a linguagem religiosa do texto bíblico, a saber, o mito e suas estruturas simbólicas e narrativas.

Uma discussão do conceito de mito na história da religião e mesmo na pesquisa bíblica está fora do alcance deste artigo. Há diferentes concepções de mito em uso nos estudos de religião, desde os que procedem da fenomenologia da religião até os conceitos que os relacionam com arquétipos psicológicos do inconsciente coletivo. Para seguirmos nosso objetivo de oferecer um conjunto articulado de questões para renovação dos MHC, abordaremos a incompatibilidade dos pressupostos e da compreensão da linguagem religiosa operantes dos MHC usando como modelo um autor que se tornou paradigmático na discussão sobre a interpretação do mito nos escritos neotestamentários. Trata-se da obra do teólogo e exegeta Rudolf Bultmann (1884-1976) e de sua proposta de como lidar com os elementos míticos presentes no texto bíblico. Alguém poderia argumentar que a postura de Bultmann em relação ao mito e à linguagem mitológica do Novo Testamento seria por demais radical. Isso pode ser correto sob um ou outro aspecto. Mas nossa avaliação é de que sua proposta para lidar como o mito no Novo Testamento teve muito mais impacto do que se reconhece. Ela está na base da forma como muitas correntes de pensamento e procedimentos interpretativos lidam com a simbologia dos textos bíblicos, inclusive na exegese latino-americana.

Bultmann publicou em 1941, portanto em plena Segunda Guerra Mundial, um pequeno, porém impactante, livro intitulado Novo Testamento e Mitologia: o problema da demitização da pregação neotestamentária ${ }^{19}$. Nessa obra, ele mapeia de forma direta um desconforto percebido pela abordagem acadêmica da Bíblia desde o século XIX e que de alguma forma se acentuava. Devemos dar esse crédito a Bultmann: ele pôs o dedo na ferida, ainda que se possa discordar da solução que ele propõe. Ele inicia seu texto constatando que a cosmovisão do Novo Testamento é mítica. O que ele entende por mito? Por mito ele entende um conjunto de pressupostos, como a construção tripartida do mundo (céu, terra, mundo subterrâneo), a concepção do mundo como palco de ação de seres sobrenaturais, como anjos, Deus e Satanás. Também inclui em sua noção de mito a construção do ser humano apresentado como não autossuficiente, afinal Satanás pode lhe incutir pensamentos maus, da mesma forma que Deus também pode dirigir seus pensamentos e ações. A história não se moveria de maneira uniforme e regular, antes seu movimento e direção seriam determinados por potências sobrenaturais. Este eon seria dominado por Satanás, pelo pecado e pela morte, mas se apres-

mundo. In: NOGUEIRA, Paulo A. S. (Org.). Religião e linguagem. Abordagens teóricas interdisciplinares. São Paulo: Paulus, 2015. p. 115-142.

19 BULTMANN, Rudolf. Neues Testament und Mythologie. Das Problem der Entmythologisierung der neutestamentlichen Verkündigung. München: Chr. Kaiser Verlag, 1985 (1941). 
saria para o seu fim, para o fim dos tempos, antecedido de dores, seguido pelo juízo, pela ressurreição dos mortos, seja para salvação, seja para danação. O problema maior reside no fato de que não é apenas o enquadramento cultural dos homens e mulheres do mundo antigo que é estruturado miticamente, mas o próprio anúncio do Evangelho também é concebido na forma do mito.

Bultmann insiste em seu argumento de que não se pode aceitar parte dessa cosmovisão apenas, rejeitando somente elementos que ferem mais a sensibilidade da modernidade e da ciência. A cosmovisão bíblica como um todo é inconsistente e incoerente com a forma moderna de ver o mundo. Não se pode exigir do homem moderno, que tem acesso à tecnologia e ciência, que acredite em relatos míticos. Isso o impediria de aceitar o anúncio do Evangelho. Dessa forma, haveria de se despir o Novo Testamento dessa cosmovisão e substituí-la por um referencial compatível com o mundo moderno, a saber, a filosofia existencial de Martin Heidegger. Nesse novo formato o anúncio do Evangelho poderia fazer sentido à humanidade.

A proposta de Bultmann teve um grande impacto na exegese bíblica do século XX. Não desconhecemos as reações negativas a ela; no entanto, entendemos que à incapacidade de lidar com a linguagem mítica que estrutura o Novo Testamento, paradigmaticamente expressa na proposta de Bultmann, subjaz o conceito de linguagem dos MHC. Bultmanianos ou não, os praticantes da exegese dos MHC têm uma agenda interpretativa no trato com os elementos míticos do texto bíblico. $\mathrm{O}$ texto bíblico é lido, em maior ou menor grau, com resistência a esses elementos.

Há vários problemas de fundo na forma da interpretação histórico-crítica, em geral, e na demitização bultmanniana, em particular. O primeiro é o pressuposto, impensável na perspectiva das ciências da linguagem e do discurso contemporâneas, da separação entre forma e conteúdo. Em perspectiva semiótica e discursiva, essa cisão entre forma e conteúdo é impensável. Um texto só é constituído a partir de um dado sistema de signos, não havendo um sentido independente deles. Seria impensável, portanto, que um núcleo de mensagem, um "anúncio", fosse mantido intacto com a troca da linguagem mítica por uma existencialista, ou qualquer outra que fosse. A mudança do código implicaria necessariamente a mudança da mensagem. Seria outra mensagem. Com isso não queremos dizer que na leitura contemporânea que fazemos dos textos bíblicos eles se mantenham inalterados, afinal, os leitores incidem nos textos por meio de seus processos interpretativos próprios. Os textos de caráter simbólico e polissêmico, como é o caso dos textos bíblicos, sempre geram novos textos nos processos de leitura. ${ }^{20}$ No entanto, a simples substituição de códigos para a manutenção de uma mensagem, com vistas à sua melhor comunicação, mostra-se totalmente inviável. Alterar os códigos de um texto é alterar seus conteúdos, que não existem independentemente deles. Ou seja, o Novo Testamento sem os relatos de curas e exorcismos, sem as lutas do messias contra as forças demoníacas, sem a chegada do reinado de Deus para substituir o eon presente, a ressurreição como vitória sobre a morte etc., não

${ }^{20}$ LOTMAN, Y. Universe of Mind. A Semiotic Theory of Culture. Bloomington, Indianopolis: Indiana University Press, 1990. p. 11ss. 
seria o texto motor da espiritualidade e da experiência religiosa de cristãos de muitas gerações, incluindo os contemporâneos.

O segundo problema na proposta de Bultmann é considerar que um texto semioticamente complexo como o texto bíblico possua apenas um nível de leitura, a saber, o nível comunicativo informacional. Um texto bíblico pertencente ao mundo do mito pode ser lido em diferentes níveis, a partir de suas imagens, estrutura narrativa, associações simbólicas, em relação com seu contexto cultural imediato, ou em conexão com estruturas profundas da psiquê etc. O processo de demitização pressupõe que o texto pode ser despido de todos esses níveis e conexões simbólico-culturais em troca de uma atualização de sua mensagem em outro código de caráter monossêmico, que aspire ao rigor da linguagem filosófica. É como se o texto bíblico tivesse como única função transmitir eficientemente mensagens sobre referentes claros e definidos. Se essas mensagens unívocas forem preservadas, em nova roupagem, o processo hermenêutico teria tido sucesso. O problema é que não combinaram esse procedimento mecânico com o texto bíblico, repleto de imagens e símbolos densos, com narrativas labirínticas, que, a despeito de não se adequarem à razoabilidade esperada pelo homem moderno, seguem sendo recriados na cultura.

Por fim, e em terceiro lugar, o projeto de demitização revela um desconforto moderno com o caráter poético do texto bíblico, com seu poder de criação de mundo por meio de narrativas e metáforas. O poder poético do texto bíblico está além do seu poder referencial. A exegese histórico-crítica, devido à sua agenda moderna, cientificista e obcecada pelo histórico-factual, não se permite apreciar o texto bíblico em sua hiperconectividade imagética e narrativa. ${ }^{21} \mathrm{O}$ projeto de demitização de Bultmann, além de avaliar mal o potencial de geração de sentido do texto bíblico, é inoportuno, face o contexto em que foi proposto. Afinal, que otimismo poderia haver na década de 1940? Que homem moderno é esse que segue projetos fascistas em guerras de extermínio e em genocídios? O período histórico no qual Bultmann fala do progresso técnico é um tempo no qual tecnologia é usada para produção de morte em massa. A linguagem mítica nas artes e na religião - e isso vale também para a linguagem mítica do Novo Testamento - parece ser a mais adequada para nos permitir vivenciar a experiência de Deus em meio ao caos e à morte, devido à sua habilidade para lidar com as ambiguidades da vida. Afinal, a geração de Bultmann vivia tempos demoníacos, tempos apocalípticos. Bultmann era tão anacrônico que evitou o potencial de interpelação da linguagem apocalíptica. Daí seu desprezo pelo mito e pelo Apocalipse de João. Não se trata, no entanto, de responsabilizarmos Bultmann por um equívoco acadêmico e por falta de sensibilidade espiritual para com o tempo em que vivia. Seu erro é, de alguma forma, o nosso erro, de todos que pretendemos nos livrar dos complexos imagéticos e narrativos da linguagem mítica do Novo Testamento, que pretendemos tornar sua mensagem asséptica, referencial e razoável. O pretenso substituto pode ser

${ }^{21}$ Sobre a hiperconectividade do texto bíblico, ver NOGUEIRA, Paulo A. S. Modo onírico de narração e de articulação de imagens: Hiperconectividade das linguagens da religião. Horizonte, v. 16, n. 51, 2018, p. 1.004-1.022. 
o existencialismo heideggeriano, ou a mediação socioanalítica marxista, o fato é que as narrativas densas e inquietas das origens do cristianismo não se deixam domesticar. Um projeto de renovação dos $\mathrm{MHC}$ necessita levar em consideração uma pauta de remitificação da leitura do Novo Testamento, de adotar teorias do mito para além das tradicionais, lançando o texto bíblico de novo no centro do nosso tempo e de nossas angústias.

\section{Para além do Sitz im Leben eclesial: as redes textuais e a cultura popular}

Na proposta de uma pauta para renovação dos MHC há um terceiro ponto que entendemos ser muito importante: o modelo de sociedade empregado. Todo estudo de religião pressupõe um modelo de sociedade. Que nível de formação social é levado em consideração? Grupos nucleares ou grandes estratos sociais? Minorias ou etnias inteiras? Que outros cortes são analisados? Gênero, sexo, etnia, classe, pertença a grupos religiosos, profissões, faixa etária? Como se organizavam internamente? Como se relacionavam com a sociedade como um todo? E ainda cabe a pergunta, no caso de uma metodologia que trabalha com textos e história: como acessar um grupo social por meio de textos do passado distante?

As respostas não são uniformes; no entanto é possível observar modelos de sociedade em ação em diferentes metodologias. No caso da crítica das formas, que se origina dos estudos de folclore do século XIX, o texto é entendido como um repositório de tradições orais. A crítica das formas não se interessa pelos evangelhos como um todo, como um artefato literário, mas como coleções de perícopes (como as catenae de milagres, por exemplo) e de núcleos narrativos (como a narrativa pré-marcana da paixão), que circularam oralmente entre as comunidades primitivas e que respondiam a certos contextos e fins (Sitz im Leben). Esse é o seu modelo de relação entre texto e grupo social. Isso faz com que o contexto social dos evangelhos seja diluído num conceito de grupo um tanto amorfo. Na crítica da redação, elaborada décadas depois, nos anos 1950, o modelo muda consideravelmente. O foco da análise não estaria nas perícopes e em sua relação atomizada com comunidades primitivas em processo de formação, mas em comunidades (Gemeinden), que seriam representadas pelos redatores, os evangelistas, seus líderes. Esses redatores coletam, organizam e finalizam relatos abrangentes sobre a vida de Jesus em resposta a necessidades dessas comunidades. Dessa forma, concebe-se uma relação praticamente circular entre evangelista (o redator) e a comunidade, ou seja, os leitores hipotéticos do texto organizados como uma igreja específica, em uma região determinada. $\mathrm{O}$ evangelista Marcos, por exemplo, coleta, seleciona e organiza materiais da tradição oral, ou de coleções escritas primitivas (tal como as catenae, por exemplo) e lhes dá um formato final com certos acentos teológicos para atender a expectativas e a problemas específicos de cada comunidade. Mas como sabemos o que pensa cada comunidade e quais os problemas contextuais que ela enfrenta? Basta ler o Evangelho de Marcos! Essa circularidade interpretativa só é possível devido ao fato que, realmente, não contamos na tradição dos evangelhos (e quiçá em todo o Novo Testamento) com autores no sentido moder- 
no. Seleção, combinação, pequenos acréscimos e acento dado ao material deveriam atender a demandas concretas de leitores específicos. ${ }^{22}$

O modelo de sociedade que prevalece na exegese histórico-crítica é, portanto, de coesão interna, de concordância quase silenciosa entre texto e leitores. Se um evangelista como Mateus usa mais o Antigo Testamento do que os demais, é porque sua comunidade seria de composição étnica judaica; se Paulo enfatiza em Gálatas a liberdade cristã contra os que exigem a circuncisão dos cristãos, é porque seus leitores, sintonizados com suas propostas, se veriam ameaçados por adversários judaizantes. No caso do Apocalipse de João, a sintonia pressuposta entre leitores e autor é ainda mais tomada de cumplicidade: ele exige que sua comunidade siga em uníssono o compromisso com o testemunho (mesmo sob risco de morte) de oposição radical contra Roma e seus aliados da província da Ásia. Em suposta sintonia com sua comunidade, ele reforçaria seu rechaço aos cristãos que se mundanizam, tornando-se assimilados pelo poder opressor. Por isso pressupõe-se que a fúria com que João se volta contra a profetiza chamada de Jezabel (em Ap 2.18-29) é partilhada por seus leitores, por sua comunidade. É como se tudo o que lemos no Apocalipse retratasse as posturas e práticas dos primeiros leitores da obra.

O modelo acima descrito e os exemplos listados evidenciam um movimento duplo da exegese histórico-crítica, a partir de seu modelo de sociedade. Por um lado, os primeiros cristãos formam comunidades relativamente harmônicas, que estabelecem relações circulares com seus líderes e com os textos organizados e produzidos por eles. Por outro lado, essas comunidades concebem a si mesmas como em total oposição ao contexto mais amplo de sua sociedade, seja o judaísmo ou o mundo mediterrâneo. Harmonia para dentro, oposição e separação radical para fora. Não encontramos aqui travestidos de investigação sócio-histórica os ideais de relações sociais dos intérpretes modernos, com seus compromissos eclesiais, projetados na história do cristianismo primitivo? Esse duplo movimento, idealizado para dentro, radicalizado para fora, se deve à ausência de diferenciação sistemática entre vida social de um grupo e sua retórica identitária. As comunidades do cristianismo primitivo apresentavam-se como harmônicas, coesas e, ao mesmo tempo, radicalmente diferentes do que lhes era externo. Esse modelo de sociedade, que toma como dado histórico a idealização do discurso, isola o cristianismo primitivo de seu entorno, criando quadros distorcidos de suas origens.

Um dos efeitos colaterais da equalização entre retórica identitária e vida social é a reconstrução das relações do cristianismo primitivo com o seu contexto a partir do discurso de exclusividade. Nele, os cristãos apresentam-se como povo de propriedade exclusiva de Deus, como sua família, como eleitos, que não devem se unir aos ímpios, pagãos idólatras politeístas. ${ }^{23}$ Curiosamente esse tipo de discurso encontramos

22 Ver crítica dessa circularidade entre comunidade e evangelista em STOWERS, Stanley. The Concept of "Community" and the History of Early Christianity. Method and Theory in the Study of Religion, 23, p. 238-256, 2011.

${ }^{23}$ Um exemplo dessa retórica de exclusividade encontramos em 1 Pedro 2.1-10. 
no Novo Testamento em 1 Coríntios $^{24}$, um dos textos que reflete uma das comunidades cristãs mais conflitivas, em total desarmonia com o apóstolo, onde não há o menor vestígio de equilíbrio entre Paulo e sua "comunidade", como se suporia numa comunidade de um dos evangelhos, como correlação de pensamento e etos entre um e outro. É também em 1 Coríntios que encontramos casos de cristãos que frequentam as festas dos cultos pagãos onde se pode comer "carnes sacrificadas" aos ídolos. Ou seja, temos diante de nós evidências de uma comunidade cristã, a despeito de acentuada retórica de exclusividade e de separação social, com fortes tensões internas, acentuadas diferenças com o apóstolo e interações socioculturais com o seu contexto maior. A exegese bíblica assumiu de forma muito unilateral, no começo do século $\mathrm{XX}$, um conceito que se tornou parte do jargão do intérprete: o conceito de "seita". Originado na sociologia de Ernest Troeltsch, "seita" é um conceito que teria o poder de oferecer consigo um quadro de reconstrução histórico-social do desenvolvimento do cristianismo no mundo antigo. O movimento religioso de Jesus de Nazaré, por exemplo, é organizado inicialmente como uma seita em torno de um líder carismático. As pessoas aderem a essa seita por conversão. Com o desenvolvimento do grupo, a liderança carismática é substituída por autoridades que ocupam cargos. Aqui surge o que sociologicamente se chama "igreja". Esse esquema teve grande impacto na pesquisa sobre o cristianismo primitivo, de forma que ainda se fala dele como "uma seita apocalíptica judaica", ou do cristianismo do final do primeiro para o começo do segundo século como um processo de "aburguesamento", de desenvolvimento de uma "grande igreja", de um catolicismo primitivo.

É verdade que a imensa diversidade da produção exegética histórico-crítica não nos permitiria afirmar que todas as análises se utilizam da mesma forma desses conceitos e desse modelo de sociedade; pode-se, no entanto, afirmar que o cristianismo é, em regra, entendido como contracultural, como um movimento na contramão dos valores e práticas das sociedades do Mediterrâneo. Como resultado desse modelo de sociedade e de inserção social do cristianismo nascente, pode-se constatar uma relativa ausência de estudos que analisam o cristianismo primitivo em relação à cultura popular de seu entorno. Afinal, de onde provêm os primeiros cristãos, aqueles que "não são de nobre nascimento", numa sociedade profundamente estratificada, na qual menos de $3 \%$ da população pertencia às elites? As comunidades cristãs não partilhavam da visão de mundo, de sensibilidades de categorias comuns aos estratos de população de onde se originavam? Eles seriam ilhas sociais no Império Romano? ${ }^{25}$

Faz-se necessário revisitar esses pressupostos sociológicos dos MHC, avaliar seus efeitos na construção de modelos de interação social dos cristãos com seu entorno, permitir hipóteses que contemplem os processos de interações e trocas culturais. Esses processos de intensas trocas culturais, que a historiografia exegética considerou

${ }^{24}$ Segundo 1 Coríntios 6.1-11, os cristãos não podem entrar com processos contra seus irmãos em tribunais de "incrédulos"; e segundo 2 Coríntios 6.14-7.1, as relações entre "crente" e "descrente" são consideradas tão incompatíveis como "a comunhão entre luz e trevas".

${ }^{25}$ Para uma discussão sobre o cristianismo primitivo e a cultura popular do Mediterrâneo, ver: NOGUEIRA, Paulo A. S. Narrativa e cultura popular no cristianismo primitivo. São Paulo: Paulus, 2018. esp. p. 47-71. 
como sincretismo do segundo século, estão desde o início determinando as formas com as quais esse incipiente movimento profético constrói sua identidade e formas de organização. Em nossa opinião, os MHC poderiam testar outros modelos sociais que o de "comunidade" e o de "seita", ou seja, de concordância harmônica interna e de separação radical para fora. Há modelos alternativos e podemos citar dois deles: um deles é de redes textuais, grupos que circulam textos entre comunidades cristãs e além, em processos intensos e dinâmicos de comunicação. Uma comunidade não precisa estar necessariamente em conformidade com o redator de um evangelho, mas poderia dialogar com diferentes versões, com modelos variados de práticas. Outro aspecto que poderia ser considerado é o de interação com a cultura popular. Os cristãos não se encontravam isolados em relação à sua sociedade e em relação a suas práticas religiosas, antes participavam dos processos de interação simbólica do seu contexto sociocultural de origem.

\section{Considerações finais}

Neste artigo nos propusemos a avaliar criticamente três pressupostos básicos de práticas de interpretação dos métodos histórico-críticos, a saber: a) a preferência pela história factual, b) uma relação moderna e, portanto, negativa para com a estrutura mítica da linguagem bíblica e, por fim, c) o conceito "comunidade". Nossa proposta é que os MHC possam ser atualizados em relação a esses três pressupostos a partir da inclusão de perspectivas contemporâneas da historiografia, dos estudos de linguagem mítica e de cultura popular.

A exegese bíblica, principalmente a partir da América Latina, tem condições de ampliar sua compreensão das categorias de percepção de mundo dos textos bíblicos, rompendo com a ênfase exclusiva em história política, econômica e militar. A consideração das memórias e das estruturas narrativas dos textos como objeto de estudo histórico permitirá uma melhor apreciação dos processos comunitários e populares de construção de sentido nas origens do cristianismo. Da mesma forma, propomos que a linguagem que era considerada no projeto bultmanniano um empecilho para a compreensão dos textos bíblicos pelo homem moderno, a saber, o mito e suas estruturas simbólicas e narrativas, seja valorizada como linguagem densa, poética, na verdade uma forma criativa de tratar dos medos e traumas humanos na história. Por fim, propomos uma substituição do conceito fechado e circular de "comunidade" e do uso acrítico dos elementos da retórica de exclusividade dos primeiros cristãos por perspectivas que permitam perceber e analisar os intensos processos de interação social e cultural nos quais eles se encontravam inseridos, em especial nos âmbitos criativos da cultura popular.

\section{Referências}

BERGER, Klaus. Exegese des Neuen Testaments. Heidelberg: Quelle \& Meyer, 1984.

BULTMANN, Rudolf. Neues Testament und Mythologie. Das Problem der Entmythologisierung der neutestamentlichen Verkündigung. München: Chr. Kaiser Verlag, 1985 [1941]. 
BURKE, Peter. O que é história cultural? Rio de Janeiro: Jorge Zahar, 2005.

CHARPENTIER, Etienne. Iniciación en el análisis estructural. Estella: Verbo Divino, 1978. CONZELMAN, Hans. Die Mitte der Zeit. Studien zur Theologie des Lukas. Tübingen: Mohr, 1954. EGGER, Wilhelm. Metodologia do Novo Testamento: Introdução aos métodos linguísticos e histórico-críticos. 5. ed. São Paulo: Loyola, 2005.

GUREVICH, A. J. Categories of Medieval Culture. London: Routledge \& Kegan Paul, 1985. LOTMAN, Y. Universe of Mind. A Semiotic Theory of Culture. Bloomington, Indianopolis: Indiana University Press, 1990.

MARXEN, Willy. Der Evangelist Markus. Studien zur Redaktiongeschichte des Evangeliums. Göttingen: Vandenhoeck und Ruprecht, 1959.

MÜLLER, U. B. Die Offenbarung des Johannes. Gütersloh: Gütersloher Verlagshaus Gerd Mohn, 1984. (ÖTK).

NOGUEIRA, Paulo A. S. Modo onírico de narração e de articulação de imagens: Hiperconectividade das linguagens da religião. Horizonte, v. 16, n. 51, 2018, p. 1.004-1.022.

NOGUEIRA, Paulo A. S. Narrativa e cultura popular no cristianismo primitivo. São Paulo: Paulus, 2018.

NOGUEIRA, Paulo A. S. Religião e ficcionalidade: modos de as linguagens religiosas versarem sobre o mundo. In: NOGUEIRA, Paulo A. S. (Org.). Religião e linguagem. Abordagens teóricas interdisciplinares. São Paulo: Paulus, 2015. p. 115-142.

SCHRÖTER, Jens. Neutestamentliche Wissenschaft jenseits des Historismus. Neuere Entwicklungen in der Geschichtstheorie und ihre Bedeutung für die Exegese urchristlicher Schriften. Theologische Literaturzeitung, Set. 2003, p. 855-866.

STOWERS, Stanley. The Concept of "Community" and the History of Early Christianity. Method and Theory in the Study of Religion, 23, p. 238-256, 2011.

THEISSEN, Gerd. Soziologie der Jesusbewegung. Ein Beitrag zur Entstehungsgeschichte des Urchristentums. München: Kaiser Taschenbücher, 1977.

WEGNER, Uwe. Exegese do Novo Testamento: manual de metodologia. São Leopoldo: EST; Sinodal, 1998.

ZABATIERO, Júlio C. Manual de exegese. São Paulo: Hagnos, 2007.

ZIMMERMANN, Heinrich. Neutestamentliche Methodenlehre. Darstellung der historischkritischen Methode. Stuttgart: Katholisches Bibelwerk, 1967.

ZIMMERMANN, Ruben. Geschichtstheorien und Neues Testament. Gedächtnis, Diskurs, Kultur und Narration in der historiographischen Diskussion. Early Christianity, 2, p. 417-444, 2011. 